\title{
SEMÂNTICA COGNITIVA: O MODELO DE DEUS PAI PROTETOR NO SISTEMA DA METÁFORA MORAL
}

\author{
Heloísa Pedroso de Moraes Feltes ${ }^{1}$ \\ Carina Maria Niederauer Granzotto ${ }^{2}$
}

\begin{abstract}
Resumo: O artigo aplica o Sistema da Metáfora Moral, no âmbito da Semântica Cognitiva de Lakoff e Johnson, ao estudo da categoria RELIGIÃo nos discursos dos imigrantes italianos católicos de 1875 à década de 50, tendo como corpus fontes documentais que provêm os discursos sob análise. $\mathrm{O}$ estudo restringe-se ao modelo de DEUS COMO PAI PROTETOR.

Palavras-chave: Semântica Cognitiva, Sistema da Metáfora Moral, Categoria RELIGIÃO.
\end{abstract}

Abstract: This article applies the Moral Metaphor System in the realm of the Cognitive Semantics of Lakoff and Johnson, to the study of the category of RELIGION in Italian Catholic immigrants' discourses from 1875 to the 1950 's. Its corpus consists of documentary sources that provide the discourses analyzed. The study is restricted to the model of GOD AS A PROTECTOR.

Key words: Cognitive Semantics, Moral Metaphor System, RELIGION category.

\section{INTRODUÇÃO}

Este artigo baseia-se num estudo mais amplo sobre a radialidade da categoria RELIGIÃO ${ }^{3}$ nos discursos dos imigrantes italianos (de 1875 à década de 1950) ${ }^{4}$. Para a construção dessa estrutura radial, utilizou-se a Teoria dos Modelos Cognitivos Idealizados, de George Lakoff (1987), aplicada metodologicamente de acordo com a proposta de Feltes (2007) para investigações de natureza cultural. Trata-se de um modelo teórico elaborado no âmbito da Semântica Cognitiva, a qual integra

1 Doutora em Lingüística Aplicada pela Pontifícia Universidade Católica do Rio Grande do Sul - PUC-RS; Docente da Universidade de Caxias do Sul - UCS. Endereço eletrônico: helocogn@terra.com.br.

2 Mestre em Letras e Cultura Regional pela UCS. Endereço eletrônico: carina.granzotto @ terra.com.br.

3 Versais ou maiúsculas referem conceitos, metáforas, metonímias e outros modelos cognitivoculturais; itens lexicais aparecem entre aspas simples e vocábulos entre aspas duplas. Quando se trata de uma referência no mundo não são usados recursos notacionais. Por exemplo: (a) estuda-se a polissemia de 'religião'; (b) a categoria RELIGIÃo é complexa; (c) "religiosidade" nesse discurso liga-se à metonímia RELIGIÃO É REALIZAR OS RITUAIS SAGRADOS.

4 A fonte de parte desse estudo encontra-se na dissertação de Carina Maria Niederauer Granzotto, orientada pela Profa. Dra. Heloísa Pedroso de Moras Feltes: Semântica Cognitiva Aplicada: a radialidade da categoria RELIGLÃO nos discursos dos imigrantes italianos (de 1875 à década de 1950). Na referida dissertação, foram analisados 93 segmentos dos 138 catalogados. 
a grande área da Lingüística Cognitiva. A estrutura radial organiza-se em torno dos modelos de DEUS COMO PAI SEVERO e de DEUS COMO PAI PROTETOR, tendo como submodelo prototípico RITUAIS. Na proposta original, toda a análise vincula-se à defesa da hipótese de uma estrutura radial para a categoria RELIGIÃO ${ }^{5}$. Essa estrutura radial, potencialmente expansível, toma esses dois modelos para DEUS no contexto de estudos sobre metáforas sobre a moralidade, que Lakoff e Johnson (1999) chamam Sistema da Metáfora Moral. O objetivo deste artigo é tratar focalmente do modelo de DEUS COMO PAI PROTETOR, nos discursos já referidos, deixando de lado uma revisão da própria Teoria dos Modelos Cognitivos Idealizados, assim como o estudo mais amplo da radialidade, cujo tratamento não é possível no espaço de um artigo.

\section{Sistema dA Metáfora Moral no Estudo dA CATEgoria REligião}

O Sistema da Metáfora Moral, proposto por Lakoff e Johnson (1999), admite que boa parte da compreensão moral do homem advém de metáforas, as quais são aplicadas a diversos domínios da experiência. Para eles, nossas idéias sobre determinados aspectos da vida nada mais são do que produtos de nossas experiências morais, resultado de mapeamentos metafóricos, através de diferentes domínios.

Os autores destacam que é importante ter sempre em mente o papel que a moralidade metafórica desempenha em nossas decisões morais. Contudo, é igualmente importante que não nos descuidemos quando o nosso sistema moral penetra de forma oculta em áreas significativas de nossa cultura, como é o caso da religião.

Os autores defendem que a Semântica Cognitiva é capaz de subsidiar de forma eficaz uma análise sobre o que são os conceitos morais e qual é a sua lógica e a isso acrescentam:

[...] virtualmente todos nossos conceitos morais abstratos - justiça, direitos, empatia, proteção, força, retidão e assim por diante - são definidos por metáforas. Isto porque não há sistema moral que não seja metafórico. Entendemos nossa experiência através dessas metáforas conceituais, raciocinamos de acordo com sua lógica metafórica e fazemos julgamentos baseados nessas metáforas. Isso é o que queremos dizer quando dizemos que a moralidade é metafórica (LAKOFF e JOHNSON, 1999, p. 325).

A universalidade dos conceitos morais, dizem, é uma questão ainda sob investigação, mas tais conceitos tendem a ter uma certa estabilidade transcultural em um dado período de tempo. Além de não serem absolutos, os conceitos morais não são impostos, nem tão pouco arbitrários. Desse modo, "qualquer visão de

5 Esse estudo na íntegra e com ampliações será publicado na obra em produção - Semântica

Cognitiva Aplicada: a radialidade da categoria RELIGLAO. 
moralidade que envolve princípios morais absolutos, definidos por conceitos literais não pode ser cognitivamente realístico para os seres humanos, cujas categorias morais muitas vezes envolvem estrutura radial, metáfora conceptual e metonímia" (LAKOFF e JOHNSON, 1999, p. 326).

Os domínios-fonte dessas metáforas teriam sua origem na maneira como as pessoas, de acordo com a história através das culturas, as entendem como possibilidade de bem-estar. Assim, as teorias populares básicas de bem-estar determinam a base do sistema das metáforas morais em todo o mundo.

Tal sistema, para Lakoff e Johnson, não é monolítico, pois é estruturado na noção de BEM-ESTAR, o que não lhe garante consistência. Dessa forma, a opção pela metáfora BEM-ESTAR É PROSPERIDADE ou BEM-ESTAR É SAÚDE dependerá basicamente da estrutura imposta pelos sistemas morais reconhecidos na família, bem como de nossos propósitos, interesses e contexto de ocorrência.

Segundo os autores, o cuidado e a proteção são elementos essenciais para o desenvolvimento do ser humano, gerando, a partir disso, uma ética da empatia e do cuidado. Partindo desse pressuposto, a FORÇA nos conduz à obtenção de nossos objetivos; logo, a FORÇA MORAL nos habilita a combater o mal. Nesse caso, o homem procura manter uma postura moral equilibrada, demonstrando forças para superar o mal, caminhando, dessa forma, rumo ao BEM-ESTAR almejado SER BOM É ESTAR EQUILIBRADO, RETIDÃO DE CONDUTA É BEM-ESTAR. O domíniofonte, nesse caso, está baseado em aspectos simples do cotidiano tais como: força, equilíbrio, saúde, prosperidade, entre outros.

Dentre os achados mais representativos dos autores e que sofreram alguns ajustes desde os primeiros estudos, citam-se aqueles que colaboram mais diretamente para esta investigação.

Levando-se em consideração o contexto da época, o maior objetivo do imigrante católico era obter bem-estar para ele e para toda sua família. Diante desse quadro, as orações representavam a possibilidade de pagar os débitos para com Deus, ao mesmo tempo em que asseguravam algum tipo de crédito, pois, de acordo com o esquema moral básico da reciprocidade, se você faz algo de bom para alguém, esse alguém ficará lhe devendo algo. Há, nesse caso, uma ação moral, uma vez que é dado algo positivo, as ORAÇÕES. Dessa forma: MAIS ORAÇÃO É MAIS BEM-ESTAR [Metáfora da Contabilidade Moral]; MAIS ORAÇÕES É MAIS SANTO [Esquema moral da reciprocidade].

Dentre os esquemas morais básicos apresentados pelos autores, apresentamse o esquema da reciprocidade e o da retribuição, uma vez serem os que melhor se aplicam à categoria RELIGIÃO. O esquema de reciprocidade está baseado em ações morais em que dar algo de valor é positivo, enquanto o contrário é uma ação imoral. Logo: se fazem algo de bom para mim, fico em débito, mas se faço algo igualmente bom a quem me fez o bem, pago de volta e ficamos quites. No esquema 
moral da retribuição, a contabilidade é feita por uma autoridade legitimada. No caso específico do objeto deste artigo, Deus é a autoridade legitimada que tem o poder de julgar, condenando ou absolvendo os pecadores. A título de exemplo, vejamos o seguinte fragmento: “[...] Entregai esse negócio a Deus que é Juiz dos vivos e dos mortos e não lhe faltarão meios para humilhar o soberbo e levantar o humilde" (BRANDALISE, 1985, p. 46).

A AUTORIDADE MORAL também surge como uma rica fonte metafórica para a análise de RELIGIÃO. Para Lakoff e Johnson (1999), é dos princípios morais da família que surge o paternalismo. Dentro desse tipo de metáfora surgem duas versões de autoridade. A primeira é a Autoridade Legitimada, ou seja, o respeito é merecido, produto do agir cuidadoso, responsável e moral por parte dos pais. A segunda versão diz respeito à Autoridade Absoluta. Nela, a autoridade está baseada na obrigação moral, por parte das crianças, de obedecer e respeitar seus pais, unicamente pelo fato de serem seus pais. Aplicada a Deus: UMA FIGURA DE AUTORIDADE É DEUS; UM AGENTE MORAL É O FIEL; MORAL É OBEDIÊNCIA.

De acordo com os autores, surge ainda a METÁFORA DA ORDEM MORAL, que é baseada na TEORIA POPULAR DA ORDEM NATURAL. Na perspectiva da ORDEM MORAL, o maior e mais forte tende a dominar o mais fraco. Como base nisso: DEUS TEM AUTORIDADE MORAL SOBRE OS HOMENS; O PADRE TEM AUTORIDADE MORAL SOBRE OS HOMENS; O HOMEM TEM AUTORIDADE MORAL SOBRE A NATUREZA.

Os autores finalizam a teoria do Sistema da Metáfora Moral com a metáfora do CUIDADO (PROTEÇÃO) MORAL. Tal metáfora exige a existência de empatia, ou seja, é necessário que se saibam quais são as necessidades dos outros para que se possa cuidar deles. Tomam como parâmetro a relação das crianças com seus pais. Nesse caso, as crianças têm direito à proteção, enquanto os pais têm o dever de provê-las e cuidá-las. Em decorrência dessa noção de cuidado/proteção, a moralidade, calcada na família, é transferida para a sociedade por meio do seguinte mapeamento: CUIDADO DA FAMÍLIA É CUIDADO MORAL; FAMÍLIA É COMUNIDADE; PAIS PROTETORES SÃO AGENTES MORAIS; CRIANÇAS SÃO PESSOAS QUE PRECISAM DE AJUDA; ATOS PROTETORES SÃO AÇÕES MORAIS.

São várias as metáforas para moralidade que estão presentes nas mais diversas culturas. Contudo, os autores consideram, como principal hipótese, que se tratam de "modelos de família que ordenam as metáforas para moralidade numa perspectiva ética relativamente coerente, por meio das quais vivemos nossas vidas" (LAKOFF e JOHNSON, 1999, p. 313). Para corroborar tal hipótese, investigam dois modelos de família que dão origem a orientações morais variadas, são eles: A MORALIDADE DA FAMÍLIA DO PAI SEVERO e A MORALIDADE DOS PAIS PROTETORES. 
A MORALIDADE DA FAMÍLIA DO PAI SEVERO está baseada no modelo nuclear de família, em que o pai é o provedor e autoridade moral máxima, a quem cabe o poder de estabelecer as regras e governar a família. Por conseguinte, os demais membros da família devem acatar e obedecer a tais regras. As regras comumente são impostas através de punições e recompensas. Já o papel da mãe, nesse modelo, é o de cuidar dos filhos e da casa, aceitando e respeitando a autoridade do pai. Com base nisso, as metáforas mais representativas desse modelo são: AUTORIDADE MORAL, FORÇA MORAL e ORDEM MORAL, ficando submetidas a elas as metáforas da EMPATIA MORAL e da PROTEÇÃO MORAL. Na MORALIDADE DOS PAIS PROTETORES, respeito e obediência são adquiridos não pela punição e pelo medo, mas, ao contrário, pelo amor. Esse modelo é freqüente nos discursos que se analisam neste artigo. Exemplo da MORALIDADE DOS PAIS PROTETORES: "Mesmo os filhos, nascidos no Brasil, partilhavam da angústia paterna - como algo herdado com o sangue - e quando o sacerdote, o religioso, o missionário estivesse em seu meio, eles se sentiam tranqüilos e felizes. [...] Deus parecia mais próximo e bem mais benigno. [...]" (ZAGONEL, 1975, p. 66-67).

O respeito a DEUS-PAI advém, segundo Lakoff e Johnson (1999), das experiências do homem em família, ou seja, metaforicamente, os pais exercem AUTORIDADE MORAL sobre os filhos, significando que o PAI manda, e os FILHOS obedecem sem que haja qualquer tipo de questionamento sobre o que é imposto.

Os autores operam ainda com a metáfora da FAMÍLIA DO HOMEM. Esta teria dois modelos distintos para a moralidade humana: um que é baseado em alguma concepção de família, e outro que é baseado na moralidade da família. Ao pensar a moralidade em geral, a partir do conceito de FAMÍLIA, surge, segundo os autores, um mapeamento metafórico que leva a inferir que toda a humanidade é uma grande família, a família dos homens. Conseqüentemente, o que se espera pela moral da obrigação é que todas as pessoas se tratem da mesma forma como tratariam os membros de sua família. Na relação entre as estruturas da moralidade humana e família chega-se a: FAMÍlIA É A HUMANIDADE; CADA CRIANÇA É CADA SER HUMANO; OUTRAS CRIANÇAS SÃO TODOS OS SERES HUMANOS; RELAÇÕES MORAIS DA FAMÍLIA SÃO RELAÇÕES MORAIS UNIVERSAIS; AUTORIDADE MORAL DA FAMÍLIA É AUTORIDADE MORAL UNIVERSAL; MORALIDADE DA FAMÍLIA É MORALIDADE UNIVERSAL; PROTEÇÃO DA FAMÍLA É PROTEÇÃO MORAL UNIVERSAL.

Dentre os candidatos a pai na Família do Homem, sugeridos pelos autores, aparece DEUS COMO PAI, que representa, na maioria das religiões, a figura de DEUS-PAI, O SER detentor do poder responsável pela ordem moral. A MORALIDADE DO PAI SEVERO fundamentaria a tradição moral ocidental, pois a criação do mundo e a ordem moral que o rege advêm desse DEUS TODO PODEROSO, cabendo aos homens o dever de aprender e praticar as leis por ele A Cor das Letras - UEFS, n. 8, 2007 
impostas. Para isso, deve-se desenvolver a força moral como forma de enfrentar o MAL existente no mundo. A relevância em manter tal atitude reside no fato de que, no dia do Juízo Final, todos serão condenados ou absolvidos de acordo com seus atos morais. Quanto a DEUS COMO PAI PROTETOR, os autores admitem ser o caso mais prototípico, intensificando a metáfora de DEUS COMO AMOR, em que se revela um Deus amoroso e repleto de compaixão que não exige, de modo radical, uma moralidade da obediência às suas leis.

Como último exemplar à moral dos PAIS surge a sociedade como um todo, e esta passa a ser concebida como FAMÍLIA. Dessa forma, as normas sociais são estabelecidas a partir das NORMAS DA FAMÍLIA, estando tudo isso ligado à metáfora do PAI SEVERO.

Dentre as teorias morais apresentadas por Lakoff e Johnson (1999), a teoria da ÉTICA CRISTÃ e a teoria da ÉTICA RACIONALISTA são as que melhor se ajustam ao estudo ora empreendido. Na ÉTICA CRISTÃ, Jesus é a manifestação maior do amor de Deus pelos homens, sacrificando, inclusive, sua vida em prol desse amor à humanidade. Nesse caso, fica clara a metáfora DEUS É AMOR, comprovando que o centro da moralidade está em desenvolver a pureza de coração, propiciando o surgimento de atos de amor mútuos. A ÉTICA RACIONALISTA aceita como verdadeira a moralidade do PAI SEVERO, porque há o entendimento de que as leis e o julgamento são produtos da racionalidade, logo a ela cabe o poder de comando, tanto para ditar as ordens, assim como para sentenciar.

Este artigo dedica-se à análise do Modelo de DEUS COMO PAI PROTETOR, de acordo com a teoria da ÉTICA CRISTÃ. Deixa-se claro, entretanto, que tanto o modelo oferecido pela ÉTICA CRISTÃ como o oferecido pela ÉTICA RACIONALISTA interagem em uma cultura, sobrepondo-se num mesmo modelo cognitivo ou modelo cultural, seja para um indivíduo, seja para uma comunidade como um todo.

\section{Modelo de Deus como Pai Protetor}

Os segmentos selecionados consistem em uma amostragem da análise do corpus, baseados na metodologia de Feltes (2007). As fontes documentais constituem-se de obras sobre histórias de famílias, cartas, estudos historiográficos, baseados em entrevistas, e estudos antropológicos sobre a imigração italiana na região Nordeste do Rio Grande do Sul. Na análise que se segue, destacam-se os modelos metafóricos e metonímicos, seus acarretamentos, e metáforas primárias e esquemas de imagens (LAKOFF e JOHNSON, 1980; LAKOFF, 1987; LAKOFF e JOHNSON, 1999). São selecionados alguns segmentos que são analisados à luz da Teoria dos Modelos Cognitivos Idealizados e, mais especificamente, do Sistema da Metáfora Moral, que se encontra incorporada a essa Teoria. 
1

Chegado ao seu novo destino, longe do convívio humano, [(a) o primeiro colono que chegou, tinha apenas o bom Deus que paternalmente por ele velasse em meio a tantos perigos, $e$ $o$ defendesse] do assalto do animal selvagem e do extermínio das enfermidades. Exausto pelo trabalho do dia, reunia à noite a sua familiazinha ao redor da parca mesa, [(b) recitava as suas breves orações e se recolhia e adormecia com a consciência tranqüila], [(c) cheia de fé na Providência Divina] [...] (BAREA, 1995, p. 14-15).

(1a) "[...] o primeiro colono que chegou, tinha apenas o bom Deus que paternalmente por ele velasse em meio a tantos perigos, e o defendesse [....

Em (1a) surge, de forma clara, a relação paternal vivida pelo imigrante com relação a Deus. Quando, no enunciado, é feita referência ao BOM DEUS, emerge uma projeção metafórica que leva a PAI PROTETOR.

Entendendo-se que PAI PROTETOR é aquele que protege seus filhos de todo o perigo, chega-se à metáfora da MORALIDADE DO PAI PROTETOR, proposta por Lakoff e Johnson (1999), a partir da qual se pode entender DEUS COMO PAI PROTETOR, o que leva à metáfora prototípica DEUS É AMOR. Nesse caso, a relação mais forte que é estabelecida é a do cuidado. Assim, com base na estrutura radial proposta: DEUS QUE É PAI PROTETOR projeta DEUS COMO PASTOR, que projeta OS FIÉIS SÃO OVELHAS DE UM REBALHO, que acarreta DEUS É AMOR POR PROTEÇÃO e SEGURANÇA.

(1c) "[o imigrante adormecia com a consciência tranqüila] cheia de fé na Providência Divina”.

Nesse recorte, o enunciado revela, a partir do Sistema da Metáfora Moral, PAI PROTETOR, como aquele que é todo amor e que obtém respeito e obediência, não por meio da punição, do medo, mais sim pelo amor e cuidado que dedica ao homem. A Providência Divina poderia estar, metonimicamente, ligada ao modelo proposicional PAI PASTOR, justamente por esse aspecto do cuidado. Assim: TER FÉ NA PROVIDÊNCIA DIVINA É TER FÉ EM DEUS, levando, metaforicamente, a: TER FÉ EM DEUS É COMO CONFIAR NO PAI.

2

$[\ldots]$

Desde o começo da colonização, esses bons colonos, vendo-se [(a) privados de toda assistência religiosa, rogaram a um sacerdote seu compatriota que aceitasse condividir com eles as privações da nova vida,] a fim de que pudessem [(b) manter viva no coração aquela $f_{2}^{\prime}$ ] que tantas lembranças suscitava da pátria distante (BAREA, 1995, p. 29).

(2a) "[os imigrantes] privados de toda assistência religiosa, rogaram a um sacerdote seu compatriota que aceitasse condividir com eles as privaçôes da nova vida [...]”.

A necessidade da presença de um sacerdote entre os imigrantes é uma evidência incontestável. A assistência religiosa, nesse sentido, atua como geradora de BEM-ESTAR capaz de fornecer forças para suportar as intempéries. 
Metonimicamente: A RELIGIÃO ASSISTE AS PESSOAS; A RELIGIÃO PROTEGE OS FIÉIS. Se: DEUS É PROVEDOR e O SACERDOTE É REPRESENTANTE DE DEUS, então: O SACERDOTE É PROVEDOR; O SACERDOTE TEM PODERES PARA SOCORRER O HOMEM; e O SACERDOTE É FONTE DE FORÇA, ENERGIA. Logo: O SACERDOTE REPRESENTA O PAI PROTETOR.

3

[(a) Rezava apelando para todas as suas devocões], [(b) mas o rosário junto aos italianos foi uma constante inquebrável. Foi o breviário do cristão, a oração para todas as necessidades.] Durante as demoradas esperas junto aos portos de embarque, prolongadas, às vezes, pelo espaço de um ou dois meses, os pobres emigrantes, sofrendo toda sorte de embaraços (passaporte, bagagens, alojamento e demais serviços burocráticos) sentiam-se perdidos e desanimados. A solução era rezar. Recitavam, então, o rosário... Cumpriam, fielmente, todas as suas devoções durante a viagem, cantando louvores à Mãe de Deus, dos pobres, dos exilados, dos aflitos, etc. ... porque [(c) somente Deus podia consolá-los e aliviar-lhes os sofrimentos] (ZAGONEL, 1975 , p. 48).

(3c) "somente Deus podia consolá-los e aliviar-lhes os sofrimentos".

Deus, como o discurso presente no corpus revela, foi, para o imigrante italiano, fonte de estímulo para suportar e aliviar seus sofrimentos. Essa relação com Deus projeta a figura do PAI PROTETOR que, em consonância com a metáfora da FAMÍLIA DO HOMEM, reforça a idéia de um DEUS PROTETOR, o qual ama e protege seus filhos. Pela moralidade do PAI PROTETOR, Deus é o modelo prototípico do AMOR, o que leva à metáfora básica DEUS É AMOR, corroborando a teoria da ética cristã.

4

$[\ldots]$

[(a) O homem reza nos momentos em que mais sente sua vocação ao infinito, mas é o mistério que lhe desperta a consciência de sua limitação e fraqueza.] O mistério não o esmaga. Revela-lhe sua vocação para a superação. É um desafio. [(b) A oração é uma tentativa de contactar com quem pode faz̧ê-lo transcender sua limitação. Quando o mistério da naturez̧a com sua violência e prepotência tranqüila de gigante o esmaga, o homem não reza. Apavora-se. Mas quando o homem, atento, percebe sua ligação intima e pessoal com Deus, ele recobra coragem e reza] (ZAGONEL, 1975, p. 49).

(4b) "A oração é uma tentativa de contactar com quem pode fazê-lo transcender sua limitação. Quando o mistério da natureza com sua violência e prepotência tranqüila de gigante o esmaga, o homem não reza. Apavora-se. Mas quando o homem, atento, percebe sua ligação intima e pessoal com Deus, ele recobra coragem e reza."

Aqui, tem-se a oração referida como um canal de comunicação entre o homem e Deus, meio pelo qual o homem expõe suas limitações. A oração surge, ainda, como forma de aplacar as forças da natureza. De acordo com Eliade (1992), 
a natureza está carregada de sacralidade, o que justificaria o temor das forças da natureza (ventos, tempestades, granizo) pelo imigrante italiano. Talvez, por acreditar nessa sacralidade da natureza, o imigrante tenha dedicado, algumas vezes, suas orações a santos específicos, como forma de proteger-se de forças sobre as quais não tinha controle. Essa natureza impõe-lhe uma força que o apavora. Contudo, sua ligação com Deus devolve-lhe a confiança, confirmando, mais uma vez, que aqui o modelo é o de DEUS COMO PAI PROTETOR. Assim, pelo esquema de LIGAÇÃO, A ORAÇÃO APROXIMA O HOMEM DE DEUS, ao mesmo tempo em que, metonimicamente, A ORAÇÃO SALVA. Como metáfora primária ORAÇÃO É PARA CIMA, pois eleva o homem em direção a DEUS.

5

$[\ldots]$

[(a) O sacerdote era para o imigrante um personagem muito importante, quase o integrador de sua personalidade e da identidade social e religiosa.] Este se sentia desintegrado sem a presença do sacerdote que se acostumara a ver e a admirar na Europa. Mesmo os filhos, nascidos no Brasil,[(b) partilhavam da angústia paterna - como algo herdado com o sangue - e quando o sacerdote, o religioso, o missionário estivesse em seu meio, ele se sentiam tranqüilos e felizes. As dificuldades eram enfrentadas com mais coragem e otimismo, Deus parecia mais próximo e bem mais benigno. Certamente o sentiam mais acessivel pois o podiam receber através do culto ministrado pelo sacerdote] [...] (ZAGONEL, 1975, p. 6667).

(5a) "O sacerdote era para o imigrante um personagem muito importante, quase o integrador de sua personalidade e da identidade social e religiosa".

Uma vez que Deus é considerado fonte de energia, capaz de garantir a sobrevivência do imigrante e, pela RELIGIÃO, ter colaborado na reconstrução da identidade social e religiosa do imigrante, o SACERDOTE, imbuído no papel de representante de Deus, metonimicamente, está por ele. Assim, atuando como elemento de LIGAÇÃO entre o homem e Deus, o SACERDOTE assume, por acarretamento dessa projeção metafórica, a figura de PAI PROTETOR. Esse modelo de PAI, pela metáfora da MORALIDADE DA FAMÍLIA DO PAI PROTETOR, representa aquele PAI que apóia e protege como parte dos cuidados que cabe ter com seus FILHOS.

(5b) "[...] partilhavam da angústia paterna - como algo berdado com o sangue - e quando o sacerdote, o religioso, o missionário estivesse em seu meio, ele se sentiam tranqüilos e felizes As dificuldades eram enfrentadas com mais coragem e otimismo, Deus parecia mais próximo e bem mais benigno. Certamente o sentiam mais acessivel pois o podiam receber através do culto ministrado pelo sacerdote".

As coisas da FÉ são, metaforicamente, tratadas como um bem herdado de família. Se A HERANÇA É UM BEM DE FAMÍlIA e A FAMÍLIA TEM LIGAÇÃO 
PELO SANGUE, então, por um acarretamento metafórico: A FÉ É HERDADA e A FÉ É HERDADA PELO SANGUE.

Sendo assim, o enunciado, ao referir a angústia paterna sentida pelo imigrante, refere, metonimicamente, a figura de DEUS-PAI que, por uma projeção metafórica, remete à figura de DEUS PROTETOR. A presença do SACERDOTE era a garantia de LIGAÇÃO com Deus através do culto ministrado por ele. Então, metonimicamente: O SACERDOTE ESTÁ POR DEUS. E, pelo esquema de LIGAÇÃO: O PADRE, ATRAVÉS DO CULTO, LIGA O HOMEM A DEUS.

\begin{abstract}
6
Basta considerar que, por várias semanas, foram obrigados a se alimentar exclusivamente com pinhões que os pinheiros lhes forneciam, fruta muito nutritiva é verdade, mas que [(a) só a Divina Providência dadivosamente lhes enviara naquele ano em profusão para evitar sua morte por inanição] (LORENZONI, 1975, p. 170).
\end{abstract}

(6a) "[pinhões] que só a Divina Providência dadivosamente lhes enviara naquele ano em profusão para evitar sua morte por inanição."

Esse recorte revela que, para o imigrante, em determinados momentos de sua nova vida, diante das dificuldades quase intransponíveis para sua sobrevivência, apenas a bondade de Deus seria capaz de garantir-lhe o alimento. Ao atribuir à Divina Providência a dádiva do alimento, o enunciado está demonstrando a influência da MORALIDADE DOS PAIS PROTETORES, ou seja, ao acreditar que Deus lhes concederia o alimento, metaforicamente, emerge a figura de um PAI, possivelmente um PAI PROTETOR que, a partir de um modelo idealizado de família, provê e protege seus filhos.

\title{
CONSIDERAÇÕES FINAIS
}

De acordo com a breve análise realizada, a percepção dos imigrantes italianos católicos, com relação à figura de Deus, atende às necessidades vividas por esses imigrantes naquele momento histórico-cultural. Tendo em vista as precárias condições em que se encontravam, quando de sua chegada, a figura de Deus que lhes ocorria era a de um PAI PROTETOR, o qual os socorreria e daria forças para suportar as dificuldades.

Dentre os domínios-fonte que contribuem para a reconstrução dos modelos cognitivo-culturais da categoria RELIGIÃO, percebe-se, no presente artigo, que a experiência moral do homem é um dos domínios de maior impacto, razão pela qual, acredita-se que a teoria do Sistema da Metáfora Moral, proposta por Lakoff e Johnson (1999), seja a que melhor represente o poder das metáforas conceituais no domínio da religiosidade. $\mathrm{Na}$ investigação com um corpus mais amplo, o Modelo do PAI PROTETOR e o Modelo do PAI SEVERO, metaforicamente expresso como 
DEUS COMO JUIZ, convivem de modo alternado ou por sobreposições de acordo com as experiências dessa cultura regional.

Mesmo com a apresentação dessa sucinta análise, utilizando um aporte teórico mínimo, mas relevante e suficiente, a partir de uma pequena amostra de segmentos, verifica-se o potencial da Semântica Cognitiva para tratar de elementos culturais, fazendo interface com estudos antropológicos, tal como proposto na ampliação metodológica elaborada em Feltes (2007) e implementada em Granzotto (2007).

\section{REFERÊNCIAS}

BAREA, D. José. A vida espiritual nas colônias italianas do Rio Grande do Sul. Trad. Mário Gardelin e Rovílio Costa. Porto Alegre: Edições EST, 1995. Trad. La vita spirituale nelle Colonie Italiane dello Statto.

BRANDALISE, Ernesto. Paróquia Santa Teresa: cem anos de fé e história 1884-1984. Caxias do Sul: Educs, 1985.

ELIADE, Mircea. O sagrado e o profano: a essência das religiões. Trad. Rogério Fernandes. São Paulo: Martins Fontes, [1957], 1992. Trad. Le sacré et le profane.

FELTES, Heloísa Pedroso de Moraes. Semântica Cognitiva: ilhas, pontes e teias. Porto Alegre: Edipucrs; São Paulo: Annablume, 2007.

GRANZOTTO, Carina Maria Niederauer. Semântica cognitiva aplicada: a radialidade da categoria RELIGIÃO nos discursos dos imigrantes italianos (de 1875 à década de 1950). Caxias do Sul: UCS, 2007. Dissertação (Mestrado em Letras e Cultura Regional), Universidade de Caxias do Sul, 2007. $326 \mathrm{p}$.

LAKOFF, George; JOHNSON, Mark. Metaphors we Live by. Chicago: The University of Chicago Press, 1980.

LAKOFF, George. Women, Fire and Dangerous Things: What Categories Reveal about the Mind. Chicago: University of Chicago Press, 1987.

LAKOFF George; JOHNSON, Mark. Philosophy in the Flesh: The Embodied Mind and its Challenge to Western Thought. New York: Basic Books, 1999.

LORENZONI, Júlio. Memórias de um imigrante italiano. Porto Alegre: Sulina, 1975.

ZAGONEL, Carlos Albino. Igreja e imigração italiana: os capucbinbos de Sabóia e seu contributo à Igreja do Rio Grande do Sul (1895-1915). Porto Alegre: Escola Superior de Teologia São Lourenço de Brindes, 1975. 
